\title{
Effect of dietary phosphorus deprivation on leukocyte function in transition cows
}

\author{
S. W. F. Eisenberg, ${ }^{1,2 *}$ L. Ravesloot, ${ }^{2,3 *}$ A. P. Koets, ${ }^{2,3}$ and W. Grünberg ${ }^{2,4} \dagger$ \\ ${ }^{1}$ Niedersächsische Tierseuchenkasse, 30169 Hanover, Germany \\ ${ }^{2}$ Department of Farm Animal Health, Faculty of Veterinary Medicine, $3584 \mathrm{Cl}$ Utrecht, the Netherlands \\ ${ }^{3}$ Wageningen Bioveterinary Research, part of Wageningen UR, 8200AB Lelystad, the Netherlands \\ ${ }^{4}$ Clinic for Cattle, University of Veterinary Medicine Hannover, Foundation, 30173 Hanover, Germany
}

\section{ABSTRACT}

Phosphorus depletion and hypophosphatemia have been described to hamper immune function in different species, an effect barely studied in dairy cows commonly developing hypophosphatemia in early lactation. Dietary P deprivation in mid lactating dairy cows was associated with a decline of the number of granulocytes and impaired granulocyte survival, whereas the phagocytic activity remained unaffected. The objective of the study reported here was to determine the effect of $\mathrm{P}$ deprivation on the leukocyte function of periparturient dairy cows. Eighteen multiparous and late pregnant dairy cows were randomly assigned to either a treatment group that was offered a markedly P-deficient diet or a control group receiving the same ration with adequate $\mathrm{P}$ content. The study consisted of a 2 -wk acclimation period that was followed by a $\mathrm{P}$ deprivation period extending from $4 \mathrm{wk}$ before to $4 \mathrm{wk}$ after parturition and a $\mathrm{P}$ repletion period of $2 \mathrm{wk}$ thereafter. Blood samples for leukocyte counts and leukocyte function analysis were obtained at the end of the acclimation period, after 2 wk of $\mathrm{P}$ deprivation, within the first week of lactation, at the end of the $\mathrm{P}$ depletion period and after 2 wk of dietary P supplementation. Blood samples for biochemical analysis were obtained weekly. Immune function was assessed by means of a phagocytosis assay and a lymphocyte stimulation test. Dietary P deprivation resulted in pronounced and sustained hypophosphatemia. Time effects were observed on the counts of different leukocyte fractions, the relative number of phagocytic granulocytes, the degree of phagocytosis, and the lymphocyte proliferation. Differences between P-deprived and control cows were only identified for the degree of phagocytosis that was lower in P-deprived cows compared with control cows. The correlation and

Received July 20, 2018.

Accepted October 26, 2018.

*Both authors contributed equally to this work.

†Corresponding author: waltergruenberg@yahoo.com regression analyses, however, revealed positive associations of the plasma phosphate concentration and the granulocyte count, the relative number of phagocytic granulocytes, and the degree of phagocytosis at the end of the dietary $\mathrm{P}$ deprivation when $\mathrm{P}$ depletion was most severe. The results of the study reported here indicate a mild negative effect of pronounced and sustained hypophosphatemia on the granulocyte count and the phagocytic activity of granulocytes in transition dairy cows. The clinical relevance of this effect for health and productivity of dairy cows remains to be determined.

Key words: hypophosphatemia, phagocytosis assay, lymphoproliferation test, immune function

\section{INTRODUCTION}

Function of the immune system in periparturient cows is an area of intensive research. Immune suppression occurring around calving is a well-recognized predisposing factor for infectious diseases such as mastitis or metritis in early lactation (Kehrli et al., 1989; Mallard et al., 1998; Hammon et al., 2006). Several metabolic disturbances have been associated with altered immune function in periparturient cows. These include ketosis and hepatic lipidosis, increased production of reactive oxygen species, as well clinical and subclinical hypocalcemia (Zerbe et al., 2000; Kimura et al., 2006; Sordillo and Aitken, 2009).

Phosphorus deficiency and hypophosphatemia have been documented to negatively affect cellular immune function in various species (Craddock et al., 1974; Kiersztejn et al., 1992; Kegley et al., 2001). In dairy cattle, hypophosphatemia that is widely believed to be suggestive of $\mathrm{P}$ deficiency is commonly observed around parturition (Grunberg, 2014). Concerns about environmental pollution with $\mathrm{P}$ of fecal origin have led to legal incentives targeted at limiting the $\mathrm{P}$ content of manure, thereby enforcing a more restrictive use of $\mathrm{P}$ in bovine nutrition. Although evidence is scant, producers and veterinarians are concerned with this development because $\mathrm{P}$ deficiency particularly around calving and 
in early lactation has empirically been associated with hampered productivity, feed intake depression, and increased risk of morbidity in the fresh cow (Grunberg, 2014). The clinical relevance of periparturient hypophosphatemia, however, remains uncertain. Although producers and veterinarians generally associate hypophosphatemia and $\mathrm{P}$ depletion in early lactation with recumbency or intravascular hemolysis of red blood cells, the effect of $\mathrm{P}$ deprivation on immune cell function of the periparturient cow has not yet been studied. One study conducted in non-periparturient dairy cows and feeding diets with varying amounts of $\mathrm{P}$, covering a range at or above current recommendations for dietary $\mathrm{P}$ content for dairy cow rations, did not reveal an effect of the dietary $\mathrm{P}$ content on the innate or cell-mediated immune response (Mullarky et al., 2009). A second study conducted in mid-lactating dairy cows and feeding a markedly P-deficient diet reported a negative effect of dietary $\mathrm{P}$ deprivation on granulocyte survival but no negative effect on the phagocytic activity of viable granulocytes (Eisenberg et al., 2014).

The objective of the study presented here was to determine if dietary $\mathrm{P}$ deprivation during the transition period alters blood-derived immune cell frequencies and function in dairy cows. We hypothesized that marked dietary $\mathrm{P}$ deprivation in late gestation would exacerbate antigen-independent immune suppression in dairy cows during early lactation.

\section{MATERIALS AND METHODS}

\section{Ethics Statement}

Procedures and treatments were approved by the Ethical Committee for Animal Experiments of Utrecht University (DEC Utrecht, permit no AVD108002016616) and performed according their regulations.

This study is part of a multi-institutional project evaluating the effect of dietary $\mathrm{P}$ deprivation in dairy cows during various stages of the production cycle. To further understand the molecular mechanisms through which P depletion may affect various organ systems of the dairy cow at different stages of the lactation cycle, other laboratories are currently conducting studies on liver and muscle tissue obtained from these transition cows. The present study focuses on the effect of dietary $\mathrm{P}$ deprivation on the leukocyte function in the periparturient period.

\section{Animals, Housing, and Feeding}

Eighteen late pregnant but still lactating HolsteinFriesian dairy cows in their second or higher lactation with an expected calving date within the same week of the year were purchased from commercial dairy farms in the Netherlands at least 1 mo before enrollment. Cows were healthy based on clinical, blood biochemical, and hematological examination and were housed in tiestalls with rubber mats covered with sawdust in a temperature-controlled facility. All animals were dried off at least $15 \mathrm{~d}$ before the start of the experiment.

\section{Study Design and Experimental Rations}

Cows participating in the study were paired by lactation number and previous 305-d lactation yield, and 1 cow of each pair was randomly assigned to the control group $(\mathbf{C O N})$ receiving a ration with adequate $\mathrm{P}$ content and the low $\mathrm{P}$ group $(\mathbf{L P})$ receiving a markedly P-deficient diet.

All cows were fed the same TMR based on corn silage, grass seed straw, and beet pulp meeting or slightly exceeding current recommendations for dairy cows with the exception of the dietary P content (NRC, 2001). While the unsupplemented base ration was offered to animals of the LP group, this same base ration was supplemented with $\mathrm{NaH}_{2} \mathrm{PO}_{4}$ to reach an adequate dietary $\mathrm{P}$ content and offered to animals of the CON group (NRC, 2001). The dietary P contents of the dry cow rations of LP and CON groups were 0.15 and $0.28 \% \mathrm{P}$ in DM and for the lactating cow rations 0.20 and $0.44 \%$ $\mathrm{P}$ in DM, respectively. The $\mathrm{P}$ content of the rations of groups LP were thus at least $40 \%$ below current recommendations for dairy cows (NRC, 2001). Cows were fed twice daily between 0600 and $0700 \mathrm{~h}$ and between 1800 and $1900 \mathrm{~h}$. Access to feed was restricted to 12.5 $\mathrm{kg}$ of DM during dry period, whereas feed was offered ad libitum after parturition. Water was available ad libitum. After parturition cows were milked twice daily between 0600 and $0700 \mathrm{~h}$ and between 1800 and $1900 \mathrm{~h}$.

The study period extended from 6 wk before the expected wk of calving to $6 \mathrm{wk}$ after the expected wk of calving. The study was initiated with a 2 -wk acclimation period from 6 to 4 wk antepartum (a.p.) during which cows of both groups were offered the balanced dry cow ration of the CON group with adequate dietary $\mathrm{P}$ content. Following the acclimation phase of the study, animals entered the P-depletion period a.p. during which cows of groups CON remained on the dry cow ration, whereas cows of the LP group were switched to the P-deficient experimental dry cow ration. Immediately after calving cows were switched to the lactating cow ration of their group and thereby entered to P-depletion period postpartum (p.p.). Four weeks after the calculated week of calving, cows entered the dietary $\mathrm{P}$ supplementation phase during which cows of both groups were fed the lactating cow ration of the CON group with adequate $\mathrm{P}$ supply. 


\section{Blood Sampling}

Blood samples were collected at the same time of the day between 0700 and $0800 \mathrm{~h}$. Blood samples for determination of the concentrations of plasma inorganic phosphate $([\mathbf{P i}]]$, plasma calcium $([\mathbf{C a}])$, plasma nonesterified fatty acids ([NEFA $]$ ), and $[\mathrm{BHB}]$ were obtained weekly. Samples for immune cell function analysis were obtained at 5 sampling times throughout the study. These were at the end of the acclimation period $\left(\mathbf{T}_{\mathbf{0}}\right), 2$ wk after onset of dietary $\mathrm{P}$ deprivation a.p. $\left(\mathbf{T}_{1}\right)$, within the first week of lactation $\left(\mathbf{T}_{2}\right)$, at the end of dietary $\mathrm{P}$ deprivation p.p. $\left(\mathbf{T}_{\mathbf{3}}\right)$, and at the end of the dietary $\mathrm{P}$ repletion period $\left(\mathbf{T}_{4}\right)$. All cows were sampled on the same day, with exception of sampling time $\mathrm{T}_{2}$. At this time samples were obtained in the middle of the week of expected calving from all cows having calved until then and $1 \mathrm{wk}$ later from the remaining cows. At $\mathrm{T}_{2}$ all cows were between 1 and $6 \mathrm{~d}$ p.p. Blood was collected by venipuncture of the jugular vein using a 20-gauge needle (Greiner Bio-One GmbH, Kremsmünster, Austria) and EDTA, Li-heparin, and serum tubes (Greiner Bio-One $\mathrm{GmbH}$ ). Leukocyte counts and leukocyte isolation were conducted in EDTA blood, whereas heparinized blood was used for the determination of plasma [Pi], [Ca], [NEFA], and [BHB]. A serum sample of each cow was collected only at $\mathrm{T}_{0}$, and a pooled serum sample of all animals was prepared that was used for the opsonization of bacteria added to the phagocytosis assay throughout the whole study.

\section{Hematology and Blood Biochemistry}

Leukocyte counts in EDTA blood were determined on an automated hematology system within $1 \mathrm{~h}$ of sample collection (Advia 120 Hematology System, Siemens Healthcare, Erlangen, Germany). Heparin tubes were centrifuged within 30 min of collection at $1,600 \times g$ for $15 \mathrm{~min}$ at room temperature. Plasma was then harvested and stored at $-18^{\circ} \mathrm{C}$ until analyzed for plasma [Pi] (ammonium molybdate method), [Ca] (Arsenazo III), [NEFA] (ACS-ACOD method), and [BHB] (UV method) using an automated blood biochemistry analyzer (ABX Pentra 400, Horiba, Europe GmbH, Langenhagen, Germany). Plasma [Ca] was analyzed to identify a possible covariance between $[\mathrm{Ca}]$ and $[\mathrm{Pi}]$; plasma [NEFA] and [BHB] were included to determine a possibly confounding effect resulting from feed intake depression observed in $\mathrm{P}$-deprived cows.

\section{Leukocyte Isolation and Phenotyping}

Leukocytes were isolated from EDTA blood under sterile conditions using osmotic lysis as described be- fore with slight modification (Eisenberg et al., 2014). Briefly, $18 \mathrm{~mL}$ of distilled water was added to $9 \mathrm{~mL}$ of EDTA blood and after $30 \mathrm{~s}$ iso-osmolarity was restored by adding $2 \mathrm{~mL}$ of $10 \times$ PBS (Lonza Group AG, Basel, Switzerland) to the sample. Samples were centrifuged at $350 \times g$ for $7 \mathrm{~min}$ at room temperature after which cells were washed twice with $10 \mathrm{~mL}$ of PBS. Cells were resuspended in RPMI (Thermo Scientific, Pierce Biotechnology Inc., Rockford, IL) and counted using a Bürker-Türk cell counting chamber (VWR International BV, Amsterdam, the Netherlands). The trypan blue exclusion method was used to determine viability of the cells, which in all samples exceeded $98 \%$. A suspension containing the desired leucocyte concentration $\left(1 \times 10^{7}\right.$ cells $\left./ \mathrm{mL}\right)$ was prepared, which was used for phenotyping, phagocytosis, and the lymphocyte stimulation assay.

For phenotyping 2 times $100-\mu \mathrm{L}$ cell suspension of each sample was added to separate wells of a roundbottom plate. Cells were centrifuged at $350 \times g$ for 4 min at room temperature after which the supernatant was discarded. Cells were resuspended and incubated with $50 \mu \mathrm{L}$ of the desired antibody mixture (see below) for $30 \mathrm{~min}$ at $4^{\circ} \mathrm{C}$ in the dark. Next, cells were washed with FACS buffer $1 \times$ PBS, $10 \%$ FCS (Lonza Group AG), and $0.1 \%$ sodium azide (Sigma-Aldrich Chemie BV, Zwijndrecht, the Netherlands)] after which the second and after repetition of the centrifugation and washing step a third antibody mixture was added. The last incubation was followed by another wash and centrifugation step before cells were resuspended in FACS buffer and analyzed by flow cytometry (BD FACSCanto II flow cytometer; Becton Dickinson Immunocytometry Systems, San Jose, CA). Cell populations were identified using different cell markers. White blood cell (WBC) populations were identified as $\mathrm{T}$ cells and natural killer cells [cluster of differentiation (CD) 2; ILA-42 biotinylated with streptavidin: Alexa Fluor 633; AbD Serotec, Kidlington, UK)], cytotoxic T cells (CD8; CC63 mouse a-bovine R-phycoerythrin; AbD Serotec), T-helper cells (CD4; CC8 mouse $\alpha$-bovine R-phycoerythrin; AbD Serotec), B cells (CD21; CC21 mouse $\alpha$-bovine FITC; AbD Serotec), and monocytes and macrophages (CD14; TUK4 mouse $\alpha$-human AlexaFluor 647; AbD Serotec). Step 1 contained CD2-biotin marker, step 2 streptavidin, and step 3 contained either the directly labeled antibodies CD4 and CD21 or CD8 and CD14.

Cell populations were identified by forward-sideward scatter (FSC-SSC; Supplemental Figure S1; https:// doi.org/10.3168/jds.2018-15417) and further separated by their fluorescence signal using the FlowJo flow cytometry analysis software (FlowJo X, TreeStar Inc., Ashland, OR). Identified relative numbers of leukocyte 
subsets were multiplied by leukocyte counts to obtain absolute cell numbers.

\section{Fluorescent Labeling of Staphylococcus aureus}

Staphylococcus aureus (strain Newbold) was grown overnight in brain heart infusion (Thermo Scientific, Pierce Biotechnology Inc.) broth at $37^{\circ} \mathrm{C}$ on a shaker set at $100 \mathrm{rpm}$. Before labeling, bacteria were washed twice with PBS. For labeling a DyLight 488 Antibody Labeling Kit (Thermo Scientific, Pierce Biotechnology Inc.) was used according to the manufacturer's instruction. After incubation, the bacterial suspension was washed 4 times in PBS to remove unbound label. Bacterial concentration was determined by measuring the optical density at $600 \mathrm{~nm}$ and aliquoted in $1.5-\mathrm{mL}$ microtiter tubes. To determine the final concentration of viable bacteria a serial 10 -fold dilution was prepared and $50 \mu \mathrm{L}$ was cultured on sheep blood agar overnight. Aliquots were stored at $-20^{\circ} \mathrm{C}$.

\section{Phagocytosis Assay}

The phagocytosis assay was performed as described before with slight modifications (Eisenberg et al., 2014). Briefly, $10 \mu \mathrm{L}$ of $S$. aureus containing $2 \times 10^{7}$ bacteria was added to a well of a 96 -well round-bottom plate and diluted with $10 \mu \mathrm{L}$ of pooled bovine serum. The bacterial suspension was incubated for $45 \mathrm{~min}$ at $37^{\circ} \mathrm{C}$ for opsonization. The WBC suspensions were kept at $37^{\circ} \mathrm{C}$ for $15 \mathrm{~min}$ to reach the desired temperature for phagocytosis. An $80-\mu \mathrm{L}$ cell suspension containing 200,000 cells was added to the bacterial suspension to achieve a final ratio of 1:100 cells to bacteria and incubated at $37^{\circ} \mathrm{C}$ for $20 \mathrm{~min}$. Phagocytosis was stopped by adding ice-cold FACS buffer to the wells and placing the microtiter plates on ice. After $5 \mathrm{~min}$ of incubation, samples were washed twice with FACS buffer and directly measured by using flow cytometry and analyzed by using FlowJo. To determine phagocytosis, FlowJo software was used for selective gating on FSC-SSC as described before (Eisenberg et al., 2014). Briefly, first all live cells were gated on FSC-SSC, then the granulocyte population was gated, and finally the degree of phagocytosis was determined by identifying the relative number of granulocytes with a fluorescent signal produced by digested labeled $S$. aureus (Supplemental Figure S2; https://doi.org/10.3168/jds.2018 -15417). Cell counts were used to determine absolute number of granulocytes and phagocytic granulocytes to distinguish between actual differences in cell function or apparent differences caused by the increase of granulocyte counts while the number of the phagocytic granulocytes does not change. The mean fluorescent in- tensity (MFI) was used as an indication of the number of labeled S. aureus ingested indicating the degree of phagocytosis. The effect of bacterial attachment during the phagocytosis assay on the fluorescence signal was investigated by incubating cells with dyed bacteria at $4^{\circ} \mathrm{C}$ and quenching cells incubated at $37^{\circ} \mathrm{C}$ with trypan blue (T8154 Trypan Blue Solution, Sigma-Aldrich, Darmstadt, Germany) before flow cytometric measurement. Neither treatment led to a change in signal compared with cells incubated according to the protocol. In addition, confocal microscopy confirmed that after phagocytosis bacteria were inside the cells, indicating that attachment of bacteria without phagocytosis was a rare event in this assay.

\section{Lymphocyte Stimulation Assay}

The lymphocyte stimulation test was performed in a 48-well format using the isolated leukocytes. The WBC were centrifuged and washed twice with Hanks' balanced salt solution (Sigma-Aldrich Chemie BV) before cells were stained with Cell Violet Trace (CellTrace Violet Cell Proliferation Kit for Flow Cytometry; Thermo Scientific, Pierce Biotechnology Inc.) according to the manufacturer's protocol. As cell culture medium, RPMI supplemented with 10\% FCS, penicillin [50 IU/ $\mathrm{mL}]$, streptomycin $[50 \mu \mathrm{g} / \mathrm{mL}$ ], and $50 \mu M$ betamercaptoethanol was used. Concanavalin A (ConA; SigmaAldrich Chemie BV) was diluted in culture medium to a final concentration of $5 \mu \mathrm{g} / \mathrm{mL}$. Under sterile conditions, $0.5 \mathrm{~mL}$ of ConA solution was added to desired wells. Culture medium without ConA was used as a negative control. Stained WBC were resuspended in 2.5 $\mathrm{mL}$ of culture medium and $0.5 \mathrm{~mL}$ of cell suspension was added to the wells prepared for the stimulation assay. Cells were incubated at $37^{\circ} \mathrm{C}$ at $5 \% \mathrm{CO}_{2}$ for 66 h. After incubation, cells were washed twice with PBS and cell proliferation was measured by flow cytometry and analyzed using FlowJo software as described with modifications (Begum et al., 2013). In short, lymphocytes were identified based on their forward sideward scatter after which the loss of fluorescent signal due to proliferation was determined (Supplemental Figure S3; https://doi.org/10.3168/jds.2018-15417). For all individual cows the percentage of cells that lost fluorescent signal in the nonstimulated condition was subtracted from the percentage found when stimulated with ConA with the unstimulated samples serving as a control.

\section{Statistical Analysis}

Data are presented as mean and standard deviation or median and interquartile range. Data were tested for normal distribution and log or exponentially trans- 
formed whenever necessary to achieve normal distribution. Repeated measures ANOVA with an autoregressive (1) covariance matrix with animal ID as subject was used to determine effects treatment, time and the interaction between treatment (random variable) and time using PROC MIXED (SAS. 9.4, SAS Institute Inc., Cary, NC). The significance level was set at $P$ $<0.05$. Bonferroni-adjusted $P$-values were used to assess differences between groups at specific sampling times whenever the $F$-test was significant. Pearson correlation analyses and backward stepwise regression analyses using PROC CORR and PROC REG (SAS. 9.4, SAS Institute Inc.) with plasma [Ca], plasma [Pi], plasma [NEFA], and plasma [BHB] as dependent variables and all variables related to leukocytes determined in this study as independent variables were conducted stratified by sampling time to identify possible effects of $\mathrm{Pi}$ and $\mathrm{Ca}$ on these parameters. A statistical software package was used for all analyses (SAS 9.4, SAS Institute Inc.).

\section{RESULTS}

All cows included in the study remained healthy until parturition and delivered healthy calves either spontaneously or with mild to moderate assistance. Clinical periparturient hypocalcemia, confirmed by blood biochemical analysis, occurred in 2 cows of the $\mathrm{CON}$ group and was characterized by apparent muscle weakness and recumbency. Clinical periparturient hypocalcemia was not observed in animals of the LP group. Cows with clinical hypocalcemia were successfully treated with oral and parenteral administration of calcium salts and thus remained in the study. Two cows in the LP group had to be removed 2 to 4 wk after parturition (after $\mathrm{T}_{2}$ ) for health reasons and thus did not complete the study. One of the 2 cows developed severe postparturient hemoglobinuria during the second week of lactation that was characterized by intravascular hemolysis and ensuing profound anemia and hemoglobinuria. The other animal had delivered twins, retained the fetal membranes, and developed metritis and ketosis. This cow was unresponsive to treatment and was removed due to deterioration. Results from these cows obtained up to and including the first week of lactation $\left(\mathrm{T}_{2}\right)$ were included in the data analysis. One cow of the CON group with abomasal displacement in the second week of lactation immediately underwent surgical correction of the condition, recovered uneventfully, and completed the study.

Differences in DMI between groups were observed from the beginning of the second week of lactation. Whereas cows of the CON group continuously increased daily feed intake from 12.5 to over $23 \mathrm{~kg}$ of
DM at the end of the depletion period, the average feed intake of P-deprived cows barely exceeded $15 \mathrm{~kg}$ of DM (Supplemental Figure S4; https://doi.org/10.3168/jds .2018-15417). Feed intake in the LP group increased within days of dietary $\mathrm{P}$ supplementation and reached the level of the CON group toward the end of the study period (data not shown). The daily milk yield of cows of the CON group at the end of the $\mathrm{P}$ deprivation period was in the range of $45 \mathrm{~kg}$, whereas cows of the LP group reached an average daily milk yield of $30 \mathrm{~kg}$ (Figure S4).

The plasma $[\mathrm{Pi}]$ time curves stratified by group are presented in Figure 1. Significant treatment, time, and treatment $\times$ time interaction effects (all $P<0.0001$ ) were observed. Plasma [Pi] in the LP group was below baseline (values measured at wk -6 relative to parturition) from wk -4 relative to calving (i.e., first week of dietary $\mathrm{P}$ deprivation) and remained below baseline until after the first week of dietary $\mathrm{P}$ repletion (Figure 1). Group differences were significant at wk -3 and during the entire deprivation period p.p. (Figure 1).

Cell counts of the different leukocyte fractions are presented in Figure 2. The total leukocyte count showed a significant time $(P<0.0001)$ but neither a treatment nor a treatment $\times$ time interaction effect (Figure 2 ). Leukocyte counts tended to increase immediately p.p. to a similar degree in both groups and declined again to an a.p. level thereafter. The granulocyte count was subject to a significant time effect $(P<0.0001)$, but not to a treatment or a treatment $\times$ time interaction effect. The number of granulocytes increased in both groups toward the time of parturition when the highest granulocyte counts were determined in both groups and declined continuously thereafter until the end of the study period (Figure 2).

Similarly the T-helper cell and the cytotoxic Tlymphocyte counts were only subject to a time effect (both $P<0.0001$ ) with lower cell counts determined at $\mathrm{T}_{2}$ and $\mathrm{T}_{3}$ compared with remaining sampling times (Figure 2). The number of monocytes and macrophages differed between sampling times $(P<0.0001)$ but not between groups or between groups at the different sampling times. These cell counts more than doubled at $\mathrm{T}_{2}$ compared with all other sampling times (Figure $2)$. B-Lymphocyte counts revealed a significant treatment and time effect $(P=0.0381$ and $P=0.0021$, respectively) with B-lymphocyte cell counts of the LP group $\left(1.14 \times 10^{3} \pm 0.31 \times 10^{3}\right.$ cells $\left./ \mu \mathrm{L}\right)$ lower than the CON group $\left(1.30 \times 10^{3} \pm 0.48 \times 10^{3}\right.$ cells $\left./ \mu \mathrm{L}\right)$. B-Lymphocyte counts were not obtained at $\mathrm{T}_{4}$ because of a technical issue.

The relative number of granulocytes (percentage of all leukocytes) and the relative number of phagocytic cells (percentage of all granulocytes) both were sub- 

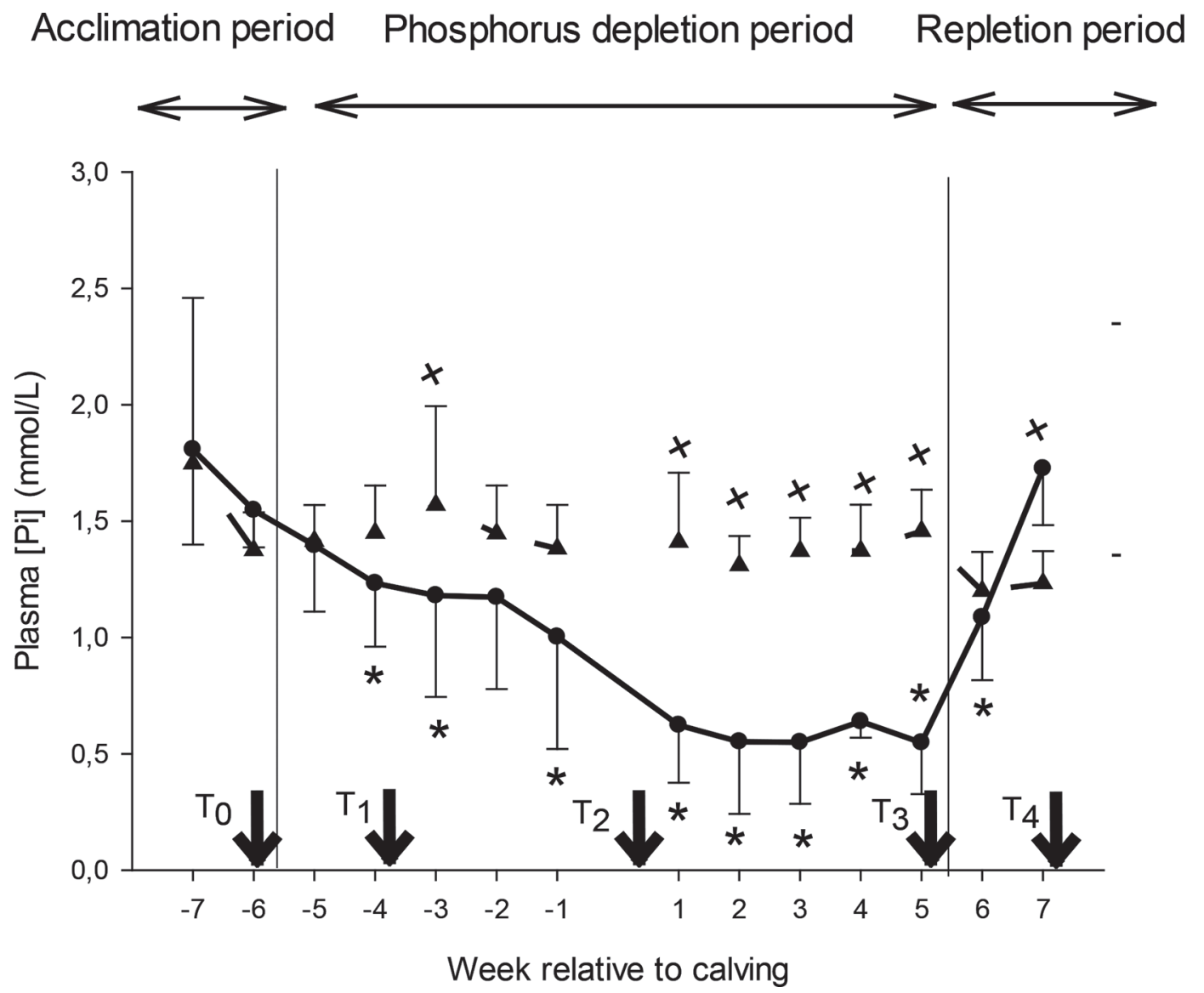

Figure 1. Mean \pm SD of plasma inorganic phosphate [Pi] of low P (LP; closed circles, solid line) group and control group (CON; closed triangles, dashed line) over time in experimental animals. Vertical solid lines mark the start and end of the P depletion phase, and a vertical dotted line represents the time of parturition. Horizontal dashed lines mark upper and lower limits of the reference for plasma [Pi] in cattle (Grunberg, 2014). Time points marked with an asterisk differ significantly from baseline values $(P<0.05$, Bonferroni corrected). Values marked with a cross differ significantly between groups $(P<0.05)$. Arrows mark the times of sample collection for leukocyte function analysis.

ject to a significant time effect $(P<0.0001)$ whereas neither a treatment nor a treatment $\times$ time interaction effect was found (Figure 3). The relative number of granulocytes determined in the phagocytosis assay tended to decrease after $T_{2}$ in both groups. At the end of the study period $\left(T_{4}\right)$ values were significantly below values determined at $T_{2}$. A similar development over time was observed when considering the absolute number of granulocytes (Figure 3). The relative number of phagocytic granulocytes dropped at the time of calving $\left(\mathrm{T}_{2}\right)$ below values determined at $\mathrm{T}_{0}$ and reached lowest values at the end of the study $\left(\mathrm{T}_{4}\right)$ in both groups (Figure 3). The absolute numbers of phagocytic granulocytes showed a similar decline at the end of the study period. At the time of calving the absolute number of phagocytic granulocytes showed an important degree of variation; however, median values at $\mathrm{T}_{2}$ tended to be higher, not lower than counts determined a.p. Mean fluorescence indices revealed a weak treatment effect $(P$ $=0.0476)$, indicating a lower degree of phagocytosis in the LP group $(6,805 \pm 2,762)$ compared with the CON group $(8,015 \pm 3,194)$. The degree of phagocytosis also tended to decrease toward $\mathrm{T}_{4}$ in both groups, the decline did, however, not reach significance level (Figure $3)$.

Induction of lymphocyte proliferation showed a significant time effect $(P<0.0001)$ but no treatment or treatment $\times$ time interaction effect (Figure 4). Induction of lymphocyte proliferation was significantly less effective at $\mathrm{T}_{3}$ compared with all other sampling times in both groups (Figure 4).

The results of the correlation analysis stratified by sampling time are presented in Table 1. A negative association between plasma $[\mathrm{Pi}]$ and plasma $[\mathrm{Ca}]$ was only determined at $\mathrm{T}_{3}$. At the same time point a positive association between plasma $[\mathrm{Pi}]$ and plasma [BHB] was identified (Table 1 ). The plasma $[\mathrm{Pi}]$ was positively associated with the total granulocyte count and the relative number of granulocytes at $T_{0}$ and $T_{3}$ as well as with the degree of phagocytosis and the relative number 

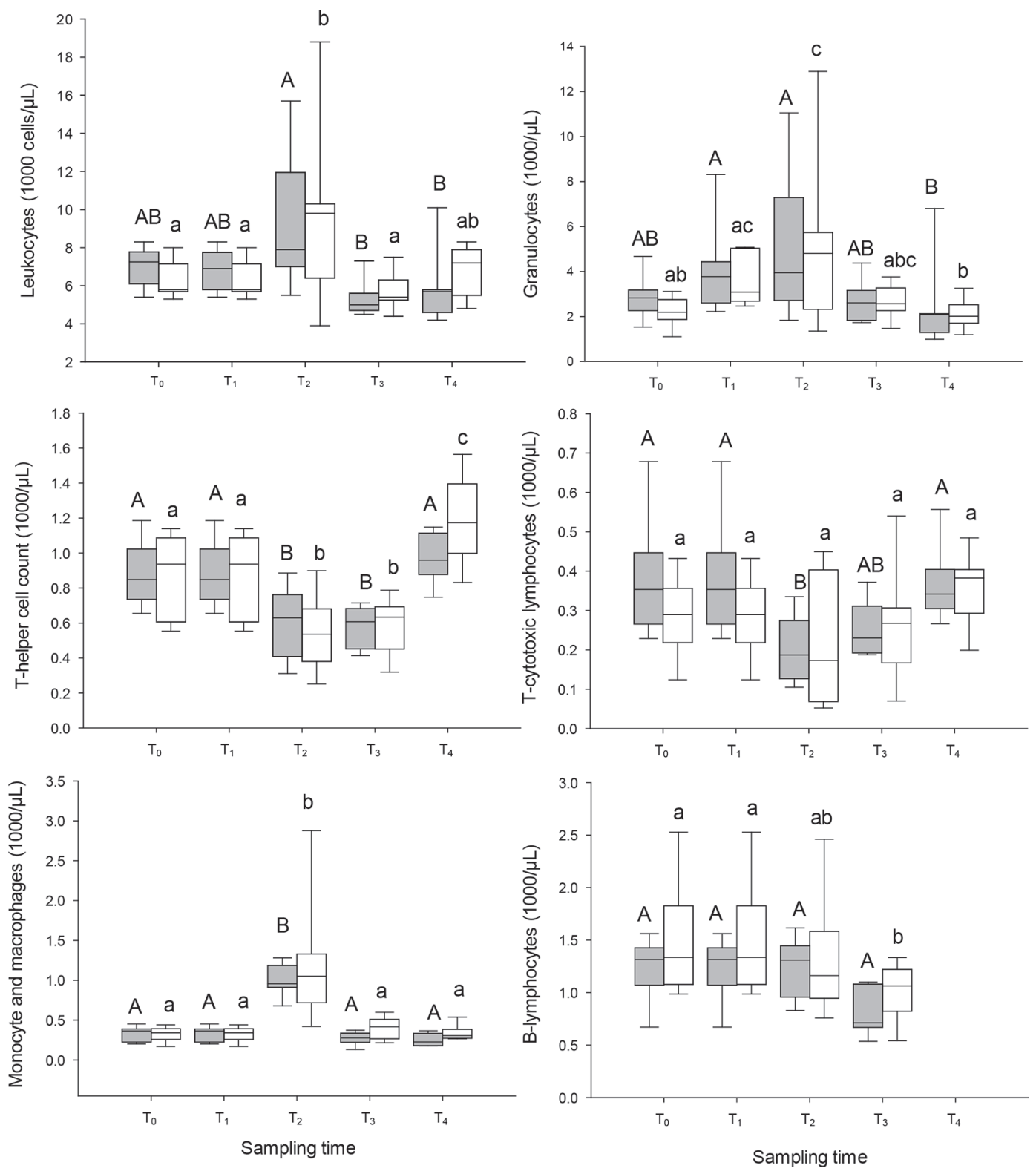

Figure 2. Leukocyte counts (upper left panel), granulocyte counts (upper right panel), T-helper cell count (middle left panel), T-cytotoxic lymphocyte count (middle right panel), monocyte and macrophage cell count (lower left panel), and B-lymphocyte cell count (lower right panel) in 100 cells $/ \mu \mathrm{L}$ (B-lymphocyte counts were not obtained at $\mathrm{T}_{4}$ because of a technical glitch) for the low P group (LP; gray boxes) and control group (open boxes) at each of the 5 sampling times. Time points with different uppercase letters differ between sampling times for the LP group; values with different lowercase letters differ between sampling times for the control group $(P<0.05$, Bonferroni corrected). Box and whisker plots represent median (horizontal line), lower and upper quartiles (bottom and top of box, respectively), as well as 2nd and 9th percentile (lower and upper end of whiskers, respectively). $\mathrm{T}_{0}=$ end of acclimation; $\mathrm{T}_{1}=2 \mathrm{wk}$ of $\mathrm{P}$ depletion antepartum; $\mathrm{T}_{2}=$ within first week of lactation; $\mathrm{T}_{3}$ $=$ end of $\mathrm{P}$ depletion, $4 \mathrm{wk}$ postpartum; $\mathrm{T}_{4}=$ after $2 \mathrm{wk}$ of $\mathrm{P}$ supplementation, $6 \mathrm{wk}$ postpartum.

of phagocytic granulocytes at $\mathrm{T}_{3}$. At $\mathrm{T}_{3}$ the plasma $[\mathrm{Pi}]$ was also negatively associated lymphocyte proliferation (Table 1). The plasma [Ca] was found to be associated with the total granulocyte count, the absolute number of phagocytic granulocytes, and the degree of phagocytosis only at $\mathrm{T}_{2}$, when none of these parameters was found to be associated with plasma $[\mathrm{Pi}]$. At $\mathrm{T}_{3}$ a negative association of the plasma $[\mathrm{Ca}]$ was identified with the monocyte and macrophage count. Negative associations with plasma $[\mathrm{NEFA}]$ were found at $\mathrm{T}_{2}$ with the degree of phagocytosis, the granulocyte count, and the absolute number of phagocytic granulocytes. A negative association with the relative number of phagocytic granulocytes was identified with plasma $[\mathrm{BHB}]$ at $\mathrm{T}_{1}$.

The results of the multiple stepwise regression analysis with plasma $[\mathrm{Pi}]$ as the independent variable yielded 

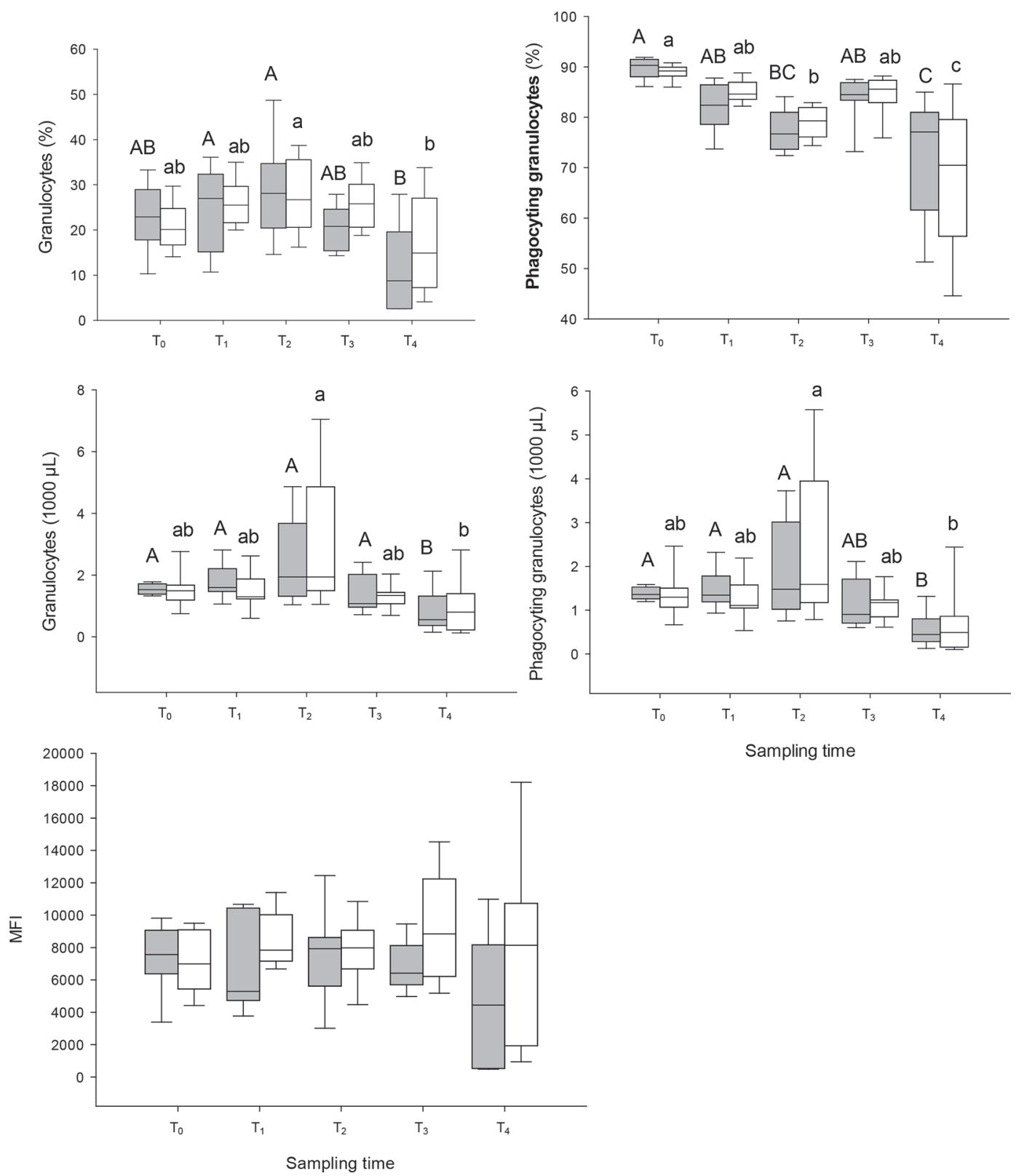

Figure 3. Granulocytes as percentage of white blood cell count in phagocytosis assay (upper left panel), phagocytosing granulocytes as percentage of all granulocytes (upper right panel), the number of granulocytes in the phagocytosis assay (middle left panel), number of phagocytosing granulocytes (middle right panel), and mean fluorescent intensity (MFI) for the low P group (LP; gray boxes) and control group (open boxes) at each of the 5 sampling times. Time points with different uppercase letters differ between sampling times for the LP group; values with different lowercase letters differ between sampling times for control group $(P<0.05$, Bonferroni corrected). Box and whisker plots represent median (horizontal line), lower and upper quartiles (bottom and top of box, respectively), as well as 2nd and 9th percentile (lower and upper end of whiskers, respectively). $\mathrm{T}_{0}=$ end of acclimation; $\mathrm{T}_{1}=2 \mathrm{wk}$ of $\mathrm{P}$ depletion antepartum; $\mathrm{T}_{2}=$ within first week of lactation; $\mathrm{T}_{3}=$ end of $\mathrm{P}$ depletion, 4 wk postpartum; $\mathrm{T}_{4}=$ after $2 \mathrm{wk}$ of $\mathrm{P}$ supplementation, 6 wk postpartum.

the strongest associations of plasma $[\mathrm{Pi}]$ at $\mathrm{T}_{0}$ with the total granulocyte count (partial $\mathrm{R}^{2}=0.526, P=$ $0.0016)$, at $\mathrm{T}_{2}$ with the percentage of lymphocyte proliferation (partial $\mathrm{R}^{2}=0.422, P=0.0048$ ) and the relative number of phagocytic granulocytes (partial $\mathrm{R}^{2}=0.188$, $P=0.0211$ ), and at $\mathrm{T}_{3}$ with the degree of phagocytosis (partial $\mathrm{R}^{2}=0.313, P=0.0272$ ). The same analysis with plasma $[\mathrm{Ca}]$ as the dependent variable showed the strongest association with the degree of phagocytosis at $\mathrm{T}_{2}$ (partial $\mathrm{R}^{2}=0.381, P=0.0083$ ) and the monocyte and macrophage cell count at $\mathrm{T}_{3}$ (partial $\mathrm{R}^{2}=0.269, P$ $=0.0476)$. Plasma $[\mathrm{NEFA}]$ was found to be associated with the relative number of phagocytic granulocytes at $\mathrm{T}_{1}\left(\right.$ partial $\left.\mathrm{R}^{2}=0.223, P=0.0479\right)$ and the degree of 


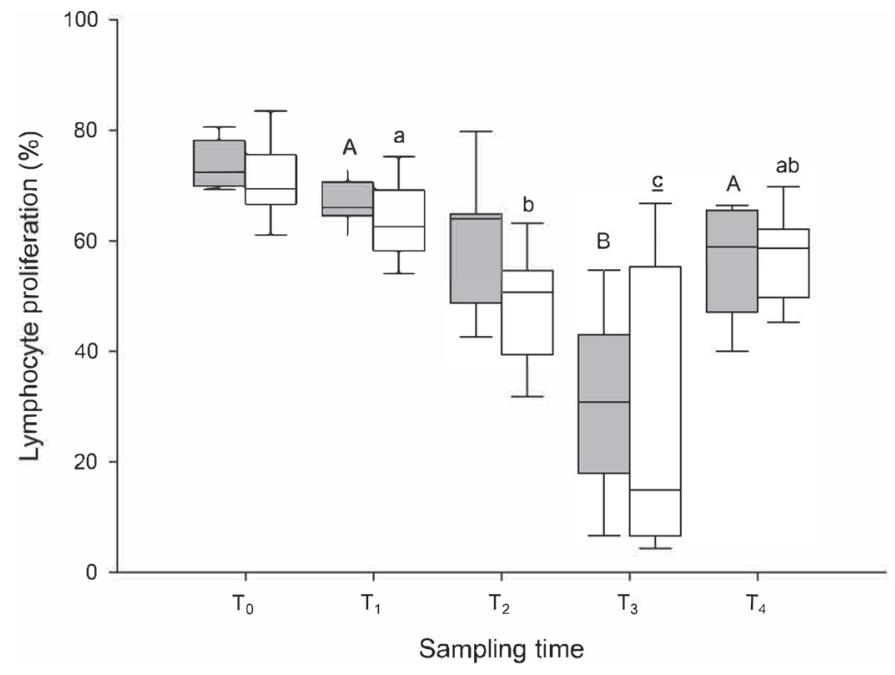

Figure 4. Lymphocyte proliferation induced by concanavalin A in percent for the low P group (LP; gray boxes) and control group (open boxes) at each of the 5 sampling times. Time points with different uppercase letters differ between sampling times for the LP group; values with different lowercase letters differ between sampling times for the control group $(P<0.05$, Bonferroni corrected). Box and whisker plots represent median (horizontal line), lower and upper quartiles (bottom and top of box, respectively), as well as 2nd and 9th percentile (lower and upper end of whiskers, respectively). $\mathrm{T}_{0}=$ end of acclimation; $\mathrm{T}_{1}$ $=2$ wk of $\mathrm{P}$ depletion antepartum; $\mathrm{T}_{2}=$ within first week of lactation; $\mathrm{T}_{3}=$ end of $\mathrm{P}$ depletion, $4 \mathrm{wk}$ postpartum; $\mathrm{T}_{4}=\operatorname{after} 2 \mathrm{wk}$ of $\mathrm{P}$ supplementation, 6 wk postpartum.

phagocytosis at $\mathrm{T}_{2}$ (partial $\mathrm{R}^{2}=0.223, P=0.0479$ ). Associations with plasma [BHB] were only identified at $\mathrm{T}_{1}$ with the relative number of phagocytic granulocytes (partial $\mathrm{R}^{2}=0.242, P=0.0381$ ).

\section{DISCUSSION}

The objective of the present study was to identify possible negative effects of $\mathrm{P}$ depletion and hypophosphatemia during the transition period on leukocytes in periparturient dairy cows. The results of the blood biochemical analysis confirm that the experimental ration of the LP group was adequate to induce pronounced hypophosphatemia with a mean plasma [Pi] of the LP group during the first weeks of lactation below $0.5 \mathrm{mmol} / \mathrm{L}$ and with several P-deprived animals with plasma [Pi] below the detection limit $(0.2 \mathrm{mmol} / \mathrm{L})$ for weeks. Differences between groups became clinically apparent only after the first week of lactation (thus after $\mathrm{T}_{2}$ ). The most prominent difference between groups was an only marginal increase in DMI from the second week of lactation in P-deprived cows that was accompanied by lower milk production. Whereas clinically apparent muscle weakness or recumbency was not observed in P-depleted cows, clinical peripartutient hypocalcemia was diagnosed in 2 animals of the $\mathrm{CON}$ group.
The results presented here indicate that hypophosphatemia had a mild effect specifically on the granulocyte count and the phagocytic activity of granulocytes. While the direct comparison of different cell counts, phagocytic activity, and results of the lymphoproliferation assay only revealed important time effects, a mild treatment effect was identified for the MFI that is an indicator for the degree of phagocytosis of granulocytes. The mean degree of phagocytosis was slightly lower in the LP group compared with the CON group. The results of the correlation and regression analysis furthermore identified significant positive associations between the plasma $[\mathrm{Pi}]$ and the absolute granulocyte count, the percentage of granulocytes, and the degree of phagocytosis at the $T_{3}$ when hypophosphatemia was most pronounced. Dietary P deprivation was reported to hamper cellular immune function in different species (Craddock et al., 1974; Fuller et al., 1976; Kegley et al., 2001). Phosphorus deficiency and hypophosphatemia in rats was associated with impaired phagocytic activity, whereas a dysfunction of granulocyte chemotaxis was described in P-depleted mongrel dogs (Craddock et al., 1974; Kiersztejn et al., 1992). In weaning pigs, lymphocyte stimulation could be modulated by the dietary P supply (Kegley et al., 2001). The mechanism behind impaired cellular immune function in states of $\mathrm{P}$ depletion has not been unequivocally unraveled, but a depletion of cellular energy stores in P-deprived leukocytes has been proposed. In rats the ATP content of leukocytes was found to be decreased in hypophosphatemic individuals. Specifically, hypophosphatemia was associated with elevated basal intracellular $\left[\mathrm{Ca}^{2+}\right]$ of leukocytes that negatively affected mitochondrial oxidation and ATP synthesis (Kiersztejn et al., 1992). In dairy cattle where hypophosphatemia is frequently observed in early lactation the effect of $\mathrm{P}$ deficiency during the periparturient period on the immune system has not been studied. One study comparing the effect of diets with a $\mathrm{P}$ content of $0.34,0.43$, and $0.52 \%$ in DM, thus meeting or exceeding current recommendation for the daily dietary $\mathrm{P}$ supply for lactating dairy cows did not observe an effect on the phagocytic activity of granulocytes or lymphocyte proliferation (Mullarky et al., 2009). An earlier study from this research group conducted in mid lactating cows that were fed a P-deficient diet $(0.18 \% \mathrm{P}$ in $\mathrm{DM})$ for 5 wk found a significantly decrease of granulocyte counts and granulocyte survival during phagocytosis as $\mathrm{P}$ deprivation progressed (Eisenberg et al., 2014). In this earlier study, the degree of phagocytosis, however, remained unaffected despite a lower relative number of phagocytosing granulocytes, suggesting no negative influence on phagocytic activity of remaining granulocytes (Eisenberg et al., 2014). Both studies thus consistently suggest a negative effect 
of $\mathrm{P}$ depletion on the absolute granulocyte count and the number of phagocytosing granulocytes, but only the present study identified an effect on the degree of phagocytosis. With the main differences between these 2 experiments being the stage of lactation of study animals and the duration of dietary $\mathrm{P}$ deprivation, both factors should be considered to be contributing to the observed differences. Prolonged P deprivation was associated with more severe and sustained hypophosphatemia in the present study, but as can be concluded from the pronounced time effects observed on various cell counts independent of the dietary $\mathrm{P}$ supply, parturition and its associated hormonal changes also have a strong effect on cellular immunity. These effects observed around parturition may well have increased the susceptibility of leukocyte function to P deficiency. Due to the study design, it is not possible to assess in how far $\mathrm{P}$ deprivation a.p. contributed to the observed effect on leukocytes at $\mathrm{T}_{3}$ and if similar effects would have been identified if $\mathrm{P}$ deprivation was limited to the p.p. period or if less pronounced $\mathrm{P}$ depletion was induced. In this context it should be noted that the degree of dietary $\mathrm{P}$ deprivation achieved in the LP group is highly unlikely to be encountered under field conditions in Europe or North America. The clinical relevance of the results of this study for example for the incidence of infectious or metabolic disease in early lactation also remains to be determined.

Table 1. Results of the Pearson correlation (r) analysis ( $P$-value in parentheses) of plasma inorganic phosphate [Pi], plasma [Ca], plasma [NEFA], and plasma [BHB] with mean fluorescent intensity (MFI), granulocyte fraction as percentage of leukocytes, number of granulocytes, number of phagocytosing granulocytes, phagocytosing granulocytes as a percentage of all granulocytes, macrophage and monocyte count, and lymphocyte proliferation induced by concanavalin A in percent stratified by sampling time ${ }^{1}$

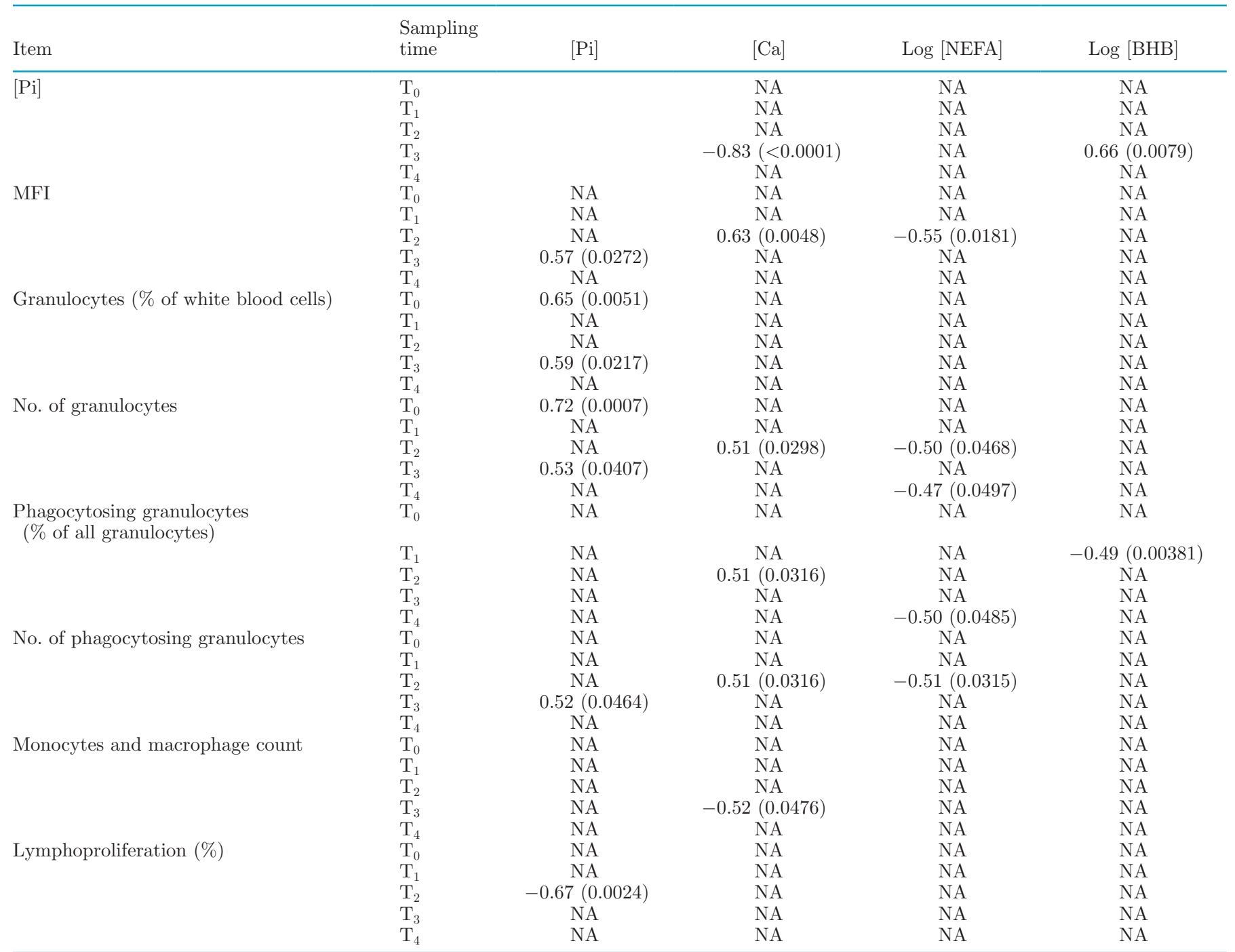

${ }^{1} \mathrm{~T}_{0}=$ end of acclimation; $\mathrm{T}_{1}=2 \mathrm{wk}$ of $\mathrm{P}$ depletion antepartum; $\mathrm{T}_{2}=$ within first week of lactation; $\mathrm{T}_{3}=$ end of $\mathrm{P}$ depletion, 4 wk postpartum; $\mathrm{T}_{4}=$ after $2 \mathrm{wk}$ of $\mathrm{P}$ supplementation, 6 wk postpartum; $\mathrm{NA}=$ no association. 
Dietary $\mathrm{P}$ deprivation in this study affected the calcium balance in the periparturient period as well as the DMI in early lactation. Both, clinical and subclinical hypocalcemia as well as negative energy balance (NEB) have been associated with hampered immune function (Hammon et al., 2006; Sordillo and Aitken, 2009). Subnormal plasma [Ca] in early in periparturient dairy cows has been proposed to negatively affect phagocytic activity of granulocytes (Kimura et al., 2006). This association would be in agreement with the positive correlations of the plasma $[\mathrm{Ca}]$ with the degree of phagocytosis and the relative number of phagocytic granulocytes after calving determined in the present study. This effect of $\mathrm{Ca}$ on immune cell function was, however, not confirmed in healthy multiparous cows with experimentally induced periparturient hypocalcemia (Kehrli and Goff, 1989). To assess if associations between plasma $[\mathrm{Pi}]$ and parameters related to leukocyte function may have been confounded by a covariance between plasma $[\mathrm{Ca}]$ and plasma $[\mathrm{Pi}]$, both parameters were included in the correlation and regression analyses. A strong negative association between $[\mathrm{Ca}]$ and $[\mathrm{Pi}]$ was only observed at $\mathrm{T}_{3}$, when $\mathrm{P}$ depletion was most severe and counter-regulatory bone mobilization presumably provided important amounts of $\mathrm{Ca}$ to the plasma pool. Because the parameters related to the phagocytic activity of granulocytes were not associated with plasma $[\mathrm{Ca}]$ at $\mathrm{T}_{3}$ when the strongest negative associations with plasma [Pi] were identified, we deem the effect of $\mathrm{P}$ deprivation on the calcium balance unlikely to have confounded the results of this study. It should, however, be noted that $\mathrm{P}$ deprivation, particularly when sustained and pronounced as in the present study, invariably also affects the Ca homeostasis through activation of osteoclastic activity and increased release of Pi together with Ca from bone (Grunberg et al., 2015). In the present study this effect was reflected in lower milk fever incidence and higher plasma [Ca] around parturition in cows of the LP group (Cohrs et al., 2018). With deficiencies of both minerals associated with negative effects on immune cell function, it would appear conceivable that the negative effect associated with plasma $[\mathrm{Ca}$ ] observed around parturition may have been blunted indirectly in P-deficient animals through an improved $\mathrm{Ca}$ balance around parturition in these animals. Inversely negative effects observed at $\mathrm{T}_{3}$ and associated with plasma [Pi] may have been softened by more elevated plasma [Ca] in P-deficient animals.

To assess the likelihood of a confounding effect of the severity of NEB resulting from feed intake depression, the plasma $[\mathrm{NEFA}]$ and $[\mathrm{BHB}]$ were also included in the correlation and regression analyses. Plasma [Pi] was found to be positively associated with $[\mathrm{BHB}]$ at $\mathrm{T}_{3}$, an effect that presumably is the result of a covariance between plasma $[\mathrm{BHB}]$ and $[\mathrm{Ca}]$ (not shown). Negative associations of plasma [NEFA] with the granulocyte counts, number of phagocytic granulocytes, and degree of phagocytosis were identified at $T_{2}$ but not at $T_{3}$ when the associations with plasma $[\mathrm{Pi}]$ were most prominent. These results support the concept that NEB in early lactation hampers immune cell function, but make it unlikely that the effects that were attributed to hypophosphatemia and were predominantly observed at $\mathrm{T}_{3}$ may have been confounded by the differences in severity of NEB in both experimental groups.

Overall, the patterns of the cell counts during the transition period observed in this study are in good agreement with results of earlier studies and did not reveal an obvious treatment effect. Increased leukocyte counts observed in both groups at $\mathrm{T}_{2}$ are primarily driven by an increase in number of granulocytes and to a lesser extent of monocytes and macrophages, whereas the counts of the other cell fractions tended to decline around calving. This observed increase in leukocyte and granulocyte counts shortly before or on the day of calving is well documented in cattle and has been attributed to increased plasma cortisol levels at the time of calving (Guidry et al., 1976). This increase in number of granulocytes and decline in number of other leukocytes at calving was followed by a return to a.p. levels at $\mathrm{T}_{3}$ and $\mathrm{T}_{4}$ as described previously (Guidry et al., 1976).

Although the relative number of phagocytic granulocytes at $\mathrm{T}_{2}$ suggests a reduction of the phagocytic capacity of granulocytes at parturition, it should be noted that the absolute number of phagocytic cells is rather increased than decreased around parturition and accordingly no decline in degree of phagocytosis was observed at $\mathrm{T}_{2}$. The comparison of the absolute cell counts with the percentage indicates, however, that the increase in absolute number of granulocytes observed around parturition is not associated with enhanced phagocytic capacity (Figure 3 ).

The lymphocyte proliferation assay revealed a marked decline in proliferation starting before parturition already and reaching a nadir at the end of the $\mathrm{P}$ deprivation period in both groups to a similar degree. At this time lymphocyte proliferation varied greatly in both groups and a strong negative association with plasma $[\mathrm{Pi}]$ was determined. Impaired functionality of lymphocytes as reflected in reduced in vitro efficiency of induction of lymphocyte proliferation in cattle has been associated with the occurrence of NEB and associated increases of plasma [NEFA] in early lactation as observed in this study (Lacetera et al., 2004). The plasma [NEFA] in study animals of both groups started to increase shortly before calving and reached peak levels in the first weeks of lactation, thereby mirroring the 
development of the efficacy of the lymphoproliferation (data not shown).

An association between hypophosphatemia and immune cell function is of particular interest for dairy cattle in early lactation as periparturient hypophosphatemia is commonly observed and periparturient immune suppression is recognized as a critical determinant for the disease incidence in early lactation (Hammon et al., 2006; Sordillo and Aitken, 2009; Grunberg, 2014). To this date, the clinical or even subclinical relevance of hypophosphatemia in fresh cows remains an issue of controversial debate and it is furthermore uncertain if periparturient hypophosphatemia is actually the result of $\mathrm{P}$ deficiency in periparturient cows. Despite this incertitude, concerns have been voiced with recent legal incentives targeting at reducing the dietary $\mathrm{P}$ content to contain environmental pollution with $\mathrm{P}$ of fecal origin, as this practice is thought to potentially exacerbate periparturient hypophosphatemia and predispose highproducing dairy cows to disease in early lactation.

In conclusion, the results of the present study reveal a mild effect of pronounced dietary $\mathrm{P}$ deprivation and ensuing hypophosphatemia on granulocyte counts and phagocytic activity of granulocytes in periparturient dairy cows as this has been established in other species. As the degree of $\mathrm{P}$ deprivation induced in this study exceeds the degree of $\mathrm{P}$ depletion and hypophosphatemia encountered under field conditions, future studies determining the threshold for severity and duration of $\mathrm{P}$ depletion in periparturient dairy cows are warranted.

\section{ACKNOWLEDGMENTS}

The study was funded by Zuivel NL, Zoetermeer, the Netherlands. The authors acknowledge the technical support of Ime Cohrs and Lennart Golbeck from the University of Veterinary Medicine Hannover, Foundation and Lianne van den Brink from Utrecht University, and the animal caretakers of the Department of Farm Animal Health at Utrecht University.

\section{REFERENCES}

Begum, J., W. Day, C. Henderson, S. Purewal, J. Cerveira, H. Summers, P. Rees, D. Davies, and A. Filby. 2013. A method for evaluating the use of fluorescent dyes to track proliferation in cell lines by dye dilution. Cytometry A 83:1085-1095.

Cohrs, I., M. R. Wilkens, and W. Grunberg. 2018. Short communication: Effect of dietary phosphorus deprivation in late gestation and early lactation on the calcium homeostasis of periparturient dairy cows. J. Dairy Sci. 101:9591-9598.
Craddock, P. R., Y. Yawata, L. Vansanten, S. Gilberstadt, S. Silvis, and H. S. Jacob. 1974. Acquired phagocytic dysfunction resulting from parenteral hyperalimentation. N. Engl. J. Med. 290:14031407.

Eisenberg, S. W. F., L. Ravesloot, A. P. Koets, and W. Grunberg. 2014. Influence of feeding a low-phosphorus diet on leucocyte function in dairy cows. J. Dairy Sci. 97:5176-5184.

Fuller, T. J., N. W. Carter, C. Barcenas, and J. P. Knochel. 1976. Reversible changes of muscle-cell in experimental phosphorus deficiency. J. Clin. Invest. 57:1019-1024.

Grunberg, W. 2014. Treatment of phosphorus balance disorders. Vet. Clin. N. Am. Food Anim. Pract. 30:383-408.

Grunberg, W., P. Scherpenisse, P. Dobbelaar, M. J. Idink, and I. D Wijnberg. 2015. The effect of transient, moderate dietary phosphorus deprivation on phosphorus metabolism, muscle content of different phosphorus-containing compounds, and muscle function in dairy cows. J. Dairy Sci. 98:5385-5400.

Guidry, A. J., M. J. Paape, and R. E. Pearson. 1976. Effects of parturition and lactation on blood and milk cell concentrations, corticosteroids, and neutrophil phagocytosis in the cow. Am. J. Vet. Res. 37:1195-1200.

Hammon, D. S., I. M. Evjen, T. R. Dhiman, J. P. Goff, and J. L. Walters. 2006. Neutrophil function and energy status in Holstein cows with uterine health disorders. Vet. Immunol. Immunopathol. 113:21-29.

Kegley, E. B., J. W. Spears, and S. K. Auman. 2001. Dietary phosphorus and an inflammatory challenge affect performance and immune function of weanling pigs. J. Anim. Sci. 79:413-419.

Kehrli, M. E. Jr., and J. P. Goff. 1989. Periparturient hypocalcemia in cows: Effects on peripheral blood neutrophil and lymphocyte function. J. Dairy Sci. 72:1188-1196.

Kehrli, M. E. Jr., B. J. Nonnecke, and J. A. Roth. 1989. Alterations in bovine neutrophil function during the periparturient period. Am. J. Vet. Res. 50:207-214.

Kiersztejn, M., I. Chervu, M. Smogorzewski, G. Z. Fadda, J. M. Alexiewicz, and S. G. Massry. 1992. On the mechanism of impaired phagocytosis in phosphate-depletion. J. Am. Soc. Nephrol. 2:14841489.

Kimura, K., T. A. Reinhardt, and J. P. Goff. 2006. Parturition and hypocalcemia blunts calcium signals in immune cells of dairy cattle. J. Dairy Sci. 89:2588-2595.

Lacetera, N., D. Scalia, O. Franci, U. Bernabucci, B. Ronchi, and A. Nardone. 2004. Short Communication: Effects of nonesterified fatty acids on lymphocyte function in dairy heifers. J. Dairy Sci. $87: 1012-1014$

Mallard, B. A., J. C. Dekkers, M. J. Ireland, K. E. Leslie, S. Sharif, C. Lacey Vankampen, L. Wagter, and B. N. Wilkie. 1998. Alteration in immune responsiveness during the peripartum period and its ramification on dairy cow and calf health. J. Dairy Sci. 81:585-595.

Mullarky, I. K., W. A. Wark, M. Dickenson, S. Martin, C. S. Petersson-Wolfe, and K. F. Knowlton. 2009. Short communication: Analysis of immune function in lactating dairy cows fed diets varying in phosphorus content. J. Dairy Sci. 92:365-368.

NRC. 2001. Nutrient Requirements of Dairy Cattle. 7th rev. ed. Nat. Acad. Sci., Washington, DC.

Sordillo, L. M., and S. L. Aitken. 2009. Impact of oxidative stress on the health and immune function of dairy cattle. Vet. Immunol. Immunopathol. 128:104-109.

Zerbe, H., N. Schneider, W. Leibold, T. Wensing, T. A. Kruip, and H. J. Schuberth. 2000. Altered functional and immunophenotypical properties of neutrophilic granulocytes in postpartum cows associated with fatty liver. Theriogenology 54:771-786. 